\title{
Dos escritoras del novecientos: Matilde Ras y Rosa M. Arquimbau
}

\author{
Dolors Madrenas Tinoco, M. ${ }^{a}$ Victoria Navas SÁncheZ-Élez \\ y JUAN M. RIBERA LLOPIS
}

(UCM)

Una de las nuevas fronteras que marca el avance del espectro socio-cultural de la modernidad es la incorporación de la mujer a la vida pública y la asunción de un protagonismo individualizado a su favor. En la paulatina consecución de ese logro, el primer tercio del siglo XX supone un tiempo crucial, tras cuyos resultados, la sociedad occidental, después del paréntesis bélico, incluso parece sufrir un retroceso. Aquellas décadas, que en la progresión literaria van desde los presupuestos modernistas a la pluralidad formal de los años treinta, propician no sólo la definitiva incorporación de nombres clásicos femeninos al canon occidental sino también la presencia coral de otras tantas autoras que profesionalizan su formación intelectual y emergen en variadas parcelas de la vida cultural; ámbitos que desde la creación artística al periodismo, a la labor editorial, a la traducción o a la acción social —en general con un discurso de reivindicación feminista-, acaban por constatarnos la existencia de una red de aportaciones femeninas nada desdeñables, soporte de las presencias acatadas críticamente como mayores.

El díptico que sigue reúne a dos nombres de origen catalán, respectivamente situados en las tradiciones peninsulares de expresión castellana y catalana. Con esas armas, Matilde Ras y Rosa M. Arquimbau vivieron y nos documentan la incorporación socio-cultural y literaria antes resumida. Las dos, además, con el paso del tiempo, alcanzarán a mirar sobre aquel primer tercio del Novecientos desde la posguerra española, no sin nostalgia y con tintes de decepción, en un horizonte que no coronó las expectativas del ciclo fundacional de su centuria. Así lo evidencian sus títulos finales, en el caso de Matilde Ras desde Portugal.

Bajo esas pautas nos permitimos emparentar a ambas autoras. Afrontadas en las líneas siguientes, bajo distintos criterios de lectura, en función del tipo de carencias que pudiera animar su particular rescate. La versión inicial de estas páginas se presentó en el Congrés Internacional Gènere i Modernitat a la Catalunya contemporània. Escriptores republicanes (UAB, 2007), mediante el formato de dos comunicaciones independientes - Matilde Ras (1881-1969): Epílogo lusitano al primer tercio del Novecientos y Rosa M. Arquimbau (19101992): Presència i papers pendents_—. La versión actual — revisada, ampliada 
y, en un caso, traducida - desea sumarse a los trabajos sobre la recuperación histórica de la presencia de la mujer y de la participación de su voz silenciada en la construcción del occidente contemporáneo. Doblemente silenciada, la mujer y su participación, cuando se trata de escritoras que no han pasado a ocupar primeras líneas en el citado canon pero cuya obra y actuación no es, en absoluto, desdeñable.

\section{MATILDE RAS (1881-1969)}

I. Polígrafa de nacimiento catalán y de expresión castellana, Matilde Ras Fernández (1881-1969) no ve su presencia sistemáticamente documentada en buena parte de la historiografía literaria castellana de referencia. Resulta significativo que, más allá de la exhaustiva recopilación de firmas por parte de F. C. Sainz de Robles (1973: T. II, 996), su nombre sólo se recupere al tratar la autoría femenina (Falcón, Simona 1992: 237-238) o como practicante de una específica parcela literaria como es la literatura infantil (Gullón 1993: T. I, 882; T. II, 1358). Amparados en ese vacío, pergeñamos el recorrido de una trayectoria literaria en la que la continuada dedicación no se verá en gran medida premiada con el resultado editorial. Acerca de sus tempranos ejercicios en prosa o en verso junto con su más afortunado hermano Aurelio hemos podido informarnos por la lectura de material epistolar compartido con Víctor Català y después aprovechado en esta aportación. Esa misma fuente notifica asimismo cómo Matilde Ras pidió consejo y puso originales en manos de firmas consagradas a la espera tanto de la corrección como del contacto editorial. Paralelamente, con una temprana atención a la grafología que le abrió la colaboración en publicaciones periódicas, Ras iniciará editorialmente su obra en esa materia con un volumen en 1917, Grafología. Estudio del carácter por la escritura (reseñado por M. Flores, Estvdio 59: 523-525, nov. 1917). A favor de ese campo, consolidaría conocimientos merced a la beca de la Junta de Ampliación de Estudios (1923-1925) para seguir en París los cursos que coronaría con el diploma de la Société Technique des Experts en Écritures. La principal plasmación de ese aprendizaje serán los dos volúmenes de finales de los años veinte e inicios de los treinta, Grafología: las grandes revelaciones de la escritura (1929) y Grafología (1933), a los que siguieron otros cinco títulos de postguerra coronados con Historia de la escritura y de la grafología (1951). Sobre esa labor se engarza su función de traductora, atenta en especial a los clásicos de la literatura infantil y juvenil, a la que aportaría su título Charito y sus hermanas (1. a ed. s. f.; 1946); pero también atenta a títulos mayores como su traducción de $E l R e$ nacimiento del conde de J. A. Gobineau (1918; se publicita desde Estvdio 69: s. p., sept. 1918) o la de textos poéticos como los catalanes después mencionados. Cabe indicar en su paso a la escritura más literaria su composición de perfiles biográficos o retratos, proyectos a favor de los cuales las cartas a Víctor Català informan de los nombres de Maquiavelo, Racine, Verlaine, Marinetti o Napoleón entre las figuras tratadas y en lo que la autora llama «reportajes», atendiendo a su extensión. Su resultado ha de hallarse repartido en las múltiples revistas en cuyas páginas colaboró, dando aquellas epístolas indicios sobre su destino, por ejemplo, el Heraldo (Madrid) en varias ocasiones. Hemos locali- 
zado en la revista Estvdio, después tratada, su texto sobre Fray Luis de León (v. Estvdio 74: 181-195, febr. 1919).

En cuanto a su producción narrativa, la edición de los títulos que en preguerra vieron la luz va estrechamente ligada a la revista y editorial Estvdio, que después atenderemos como publicación periódica para testimoniar la diversidad de materiales concebidos por la autora. Tenemos noticia de una novela y un volumen de relatos aparecido en dicha editorial (Sainz de Robles 1973: T. II, 996) - Quimerania (que, por ejemplo, se publicita desde Estvdio 69: s.p., sept. 1918) y Cuentos de la guerra (anunciada en Estvdio 15: s.p., marzo 1916) - que todavía no hemos podido localizar. Sí contamos con la lectura de Donde se bifurca el sendero (1913), aparecida primero en la revista y después cuidadosamente publicada por la editorial homónima (M. Ras, Estvdio, v. nota 3, v. tb. Estvdio 9: 465-466, sept. 1913 sobre su éxito y anuncio de edición de lujo). Novela corta anclada desde el inicio en tópicos postochocentistas como la doble especialización urbe/campo o los retratos que alternan trazos literarios interesantes con lugares comunes heredados de la literatura folletinesca. La obra acierta en la agilidad de sus diálogos, que contrastan el registro culto urbano y el popular de raíz campesina, y traen a colación, por el origen de uno de los personajes femeninos, aragonesismos y catalanismos que la autora conoce por propia genealogía. Ras, no obstante alguna de esas rémoras, maneja rasgos narrativos de época - así, la inclusión de episodios tratados como texto teatral, con entrada de diálogos, pies dramáticos y disposición de la respectiva escena- $-y$ alude a recursos coetáneos en alza, como por ejemplo, la referencia a un «monólogo interno» del protagonista (Ras 1913: 51), que no pasará de una sencilla meditación. Cuadro previsto de opuestos éticos, la creciente trama de personajes solventemente manejada supera la inicial expectativa de lectura y sorprende con el final que sacude los valores más tradicionales: así, el sólido matrimonio burgués sucumbe ante la afirmación de la aventura del marido y la seguridad de la amante, la joven campesina de origen aragonés traída a la capital madrileña por el señorito adúltero desde la provincia abulense. Esa fluctuación entre componentes narrativos rancios y atisbos de modernidad formal y ética se evidencia también en la producción teatral de Ras, que llegó a editarse en el volumen conjunto Teatro de mujeres (1934), con obras de Halma Angélico (pseudónimo de M. ${ }^{a}$ Francisca Clar Margarit) y Pilar de Valderrama. El libro reúne dos piezas suyas, El amo y El taller de Pierrot, subtituladas como drama y farsa. En el primer título late condensadamente el esquema guimeraniano de la joven acosada por el amo y redimida por un mozo, con tono de revuelta de clases; en el segundo, a la conexión benaventiana de sumarse a la recuperación hispana de la commedia dell'arte, hay que añadir el nexo con el teatro simbolista rusiñolesco, haciendo suyos debates en torno a arte y sociedad. La presencia de Guimerà y de Rusiñol en Ras se justifica doblemente desde sus lecturas directas de las letras catalanas y desde el éxito y divulgación que una y otra firma tuvieron en castellano. Fórmulas dramáticas, incluso con variantes evolucionadas, que seguían siendo válidas en la escena de los años veinte y treinta. Eso justificaría su selección en el volumen mencionado. Por su parte, el prologuista, además de razonar la existencia de un teatro de mujeres por razón de autoría y de temática, a propósito de Ras alude tanto a 
las «reminiscencias» que evidencia su escritura como a sus «entrañas modernas» (Ras et alii 1934: 15).

La autora dejó muchas páginas escritas en prensa diaria y revistas literarias, desde El Sol a Blanco y Negro (Sainz de Robles 1973: T. II, 996). Como muestra de esa labor, hemos vaciado Estvdio (Barcelona, 1913-1920) donde su prolífica firma acompaña traducciones de lírica latina, francesa, portuguesa, rusa o provenzal y, de entre los modernistas catalanes, a Víctor Català y a Joan Maragall; así mismo de textos que, genealógicamente, emparentan con sus «reportajes» ${ }^{\text {. }}$. No menos interesante fue la participación como reseñadora, presentando sorprendentemente textos de historia o de economía - a no ser que las siglas M. R., por lógica, correspondan al colaborador Manuel Reventós-, también sobre pintura o literatura, como en el caso de un volumen de su admirada Víctor Català 2 .

${ }^{1}$ Ras, M., Estvdio: «A una mano de mármol hallada en el Ródano», «Mi tumba» de F. Mistral, 7: 67-68, jul. 1913; «A Apolo», «Al dios fauno», «A Venus», «A Sestius» de Horacio, 8: 194-197, ag. 1913; «Descartes» de P. Landormy, 9: 396-493, sept. 1913; «El amor caído» de P. Verlaine, 10: 45, oct. 1913; «Las rosas marchitas» de P. Bourget, 13: 123-124, en. 1914; «A François Coppée invernando en Cannes (1893)», «Anda que te andarás a tu país volverás» de F. Mistral, 16: 98-100, abr. 1914; «El almendro», «Después de la tempestad» de Juan de Maragall, 17: 332-333, m. 1914; «La noche», «Sé donde», «El último sol» de E. Verhaeren, 19: 99-102, jul. 1914; «Las fiestas de Navidad y Epifanía» de E. Vancandard, 24: 385-403, dic. 1914, y 25: 28-43, en. 1915; «Sonetos» de Antero de Quental, 28: 61-74, abr. 1915; «Los árboles viejos (siglo XVIII)» de V. Catalá, 30: 436, jun. 1915; «La noche purísima» de J. Maragall, 36: 433, dic. 1915; «A la rota» de J. M. Guyau, 33: 385-386, ag. 1915; «A mi hija Adela» de V. Hugo, 39: 393-394, mar. 1916; «Fin de año» de J. Maragall, 48: 384, dic. 1916; «La labradora» de E. Verhaeren, 51: 407, mar. 1917; «El zuequero» de E. Verhaeren, 57: 415, sept. 1917; «Lo inaccesible» de Gauthier-Ferrières, 59: 220, nov. 1917; «La hora excesiva» de Mme. Basset d'Auriac, 68: 213, ag. 1918; «Los huéspedes de diciembre» de E. Verhaeren, 72: 393, dic. 1918; «A Adrien Remacle» de P. Verlaine, 73: 70, en. 1919; «Marco Aurelio» de V. Delbos, 76: 1-28, abr. 1919; «Lucrecio» de V. Delbós, 77: 157-178, m. 1919; «Primavera» de V. Hugo, 77: 224, m. 1919; «Los monjes» de E. Verhaeren, 80: 46, ag. 1919; «Torcuato Tasso», 82: 38-52, oct. 1919; «Kant» de V. Delbós, 83: 175-199, nov. 1919 y 84: 317-341, dic. 1919; «Otoño» de V. Hugo, 83: 214, nov. 1919; «En el norte» de E. Verhaeren, 85-86: 59, en.febr. 1920; «Sócrates» de V. Delbós, 87: 300-320, mar. 1920; «Cap y Cua» de V. Català, 92: 238240, ag. 1920; «El abuelo» de I. S. Nikitine, 95: 208, nov. 1920; «Spinoza» de V. Delbós, 96: 379418, dic. 1920.

${ }^{2}$ Ras, M., Estvdio, 'Revista de Revistas': H. Philouze «Las condiciones en que se presenta actualmente el crédito de los Estados balcánicos», y M. Frère «Las repercusiones económicas de la guerra balcánica», 14: 306-308, febr. 1914; L. Brentano «Dificultades en la investigación económica», 19: 118-120, jul. 1914; E. Pichón «La intervención japonesa», 28: 105-106, abr. 1915. 'Bibliografía': P. Leroy-Beaulieu La question de la population, 14: 333-335, febr. 1914; J. Ceballos Teresi Nuestro problema monetario, 15: 495-497, mar. 1914; Cámara de Comercio y Navegación Memoria comercial del año 1912, 15: 498-499, mar. 1914; G. Schmoller Charakterbilder, 15: 505506, mar. 1914; Ch. Schmidt Les débuts de l' industrie cotonnière en France (1760-1806), 15: $512-$ 513, mar. 1914; A. Fontaine et alii La concentration des entreprises industrielles et comerciales, 16: 181, jun. 1914; H. Key La vie économique de la Suède, 16: 375-377, jun. 1914; D. Bellet La nouvelle voie maritime. Le canal de Panama, 18: 529-537, jun. 1914; F. Flora Le finanze della guerra, 18: 555-557, jun. 1914; Th. Duret Histoire de J. Mc N. Whistler et de son æeuvre, 29: 362-365, m. 1915; F. Lifschitz Die historische Schule der Wirtschaftswissenschaft, 30: 521-524, jun. 1915; J. W. Mackail Russia's gift ot te [sic] world, 32: 310-312, ag., 1915; F. Oppenheimer Weltwirtschaft und Nationalwirtschaft, 32: 312-315, ag. 1915; Statisches Jahrbuch für das Deutsche Reich, 35: 
Así mismo, colaboró como narradora ${ }^{3}$. Sus relatos más o menos extensos —entre el cuento y la novela corta y que sólo hemos encontrado en las páginas de Estvdio- oscilan entre la ambientación burguesa y la popular, en espacios narrativos como Madrid o pueblos verificables o literaturizados. Se tiende en ellos a la galería variada de personajes, burgueses de nivel medio-alto madrileños o tipos proyectados desde cierta tópica costumbrista; los unos afirmados mediante referencias cultas a las letras, la música y las artes plásticas o también merced al cotejo de hábitos urbanos, los otros asentados en la sencillez o la visceralidad de sus reacciones y en ocasiones en su habla, aunque de modo menos acentuado que en Donde se bifurca el sendero. A sus relatos de ambientación campesina, añadiremos algunos textos firmados con el hipotético pseudónimo de Pepita Real: un cuento y una estampa-reportaje sobre Gredos que, por temas y escrituras, atribuimos a Ras, junto con una rememoración de Galdós. De aquellos firmados por ella y donde acierta con formas narrativas que van de la nouvelle de signos cosmopolitas - así su llamada a la literatura del subconsciente o sobre el auge de las corrientes teosóficas - a la prosa de fondo decadente, a la estructura dietarística o al cuadro histriónico que apura los ángulos de un Madrid de fondo galdosiano, destacaremos un relato. Se trata de La Muerte, dedicado a Víctor Català. Este texto tiene mucho de juego de tablero donde el protagonista se encara con la Parca, y que se corresponde con el gusto por el ajedrez que la autora revelará en su Diario (Ras 1946: 28, 34, 65). Tanto aquí como en el texto atribuido de ambientación rural se reconoce la factura de la fábula. Junto a esos trabajos en prosa, ordenamos asimismo alguna colaboración que se mueve en el terreno de la meditación y de la información literaria, sobre pintura y también grafología, o acerca de la traducción o de alguna cuestión de alcance social como el feminismo ${ }^{4}$. Además la revista contiene reseñas y traducciones firmadas por M. y R., que cabe considerar de la autora, así como las rubricadas como X.X (v., por ejemplo, más traducciones de lírica portuguesa - Estvdio 2: 217-219, febr. 1913; 62: 258, febr. 1918; 52: 46, abr. 1917; 71: 235, nov. 1918; 74: 216, febr. 1919; 82: 53, oct. 1919—, o inglesa — 93: 418, sept. 1920).

308, nov. 1915; E. Tormo y Monzó Jacomart y el Arte hispanoflamenco cuatrocentista, 45: 548551, sept. 1916; J. Sachs La pintura francesa moderna fins el cubisme, 69: 506-508, sept. 1918; F. A. de Icaza El Quijote durante tres siglos, 72. 480-483, dic. 1918; V. Català La Mare-Balena, 93 : 507-508, sept. 1920.

${ }^{3}$ Ras, M., Estvdio: Mis elecciones (novela corta), 1: 35-46, en. 1913; Primavera (cuento), 3 : 350-355, mar. 1913; Donde se bifurca el sendero, 4: 113-141, abr. 1913; 5: 268-301, m. 1913; 6: 431-458, jun. 1913; 7: 137-153, jul. 1913; El puerto (novela corta), 8: 249-298, ag. 1913; Ciento y el mono (cuento), 9: 347-355, sept. 1913; El puente roto, 10: 140-150, oct. 1913; La muerte (cuento), «A Víctor Catalá», 12: 446-451, dic. 1913. Real, P., Estvdio: Arrogante (cuento campesino), 1: 118-124, en. 1913; «Gredos», 8: 198-200, ag. 1913; «Galdós», 85-86: 53-58, en.-febr. 1920.

${ }^{4}$ Ras, M., Estvdio: «Los personajes del Quijote», 2: 203-216, febr. 1913; En torno a la guerra, «Literatura alemana sobre la guerra», 28: 104-106, abr. 1915, «Figuras del Quijote. Los personajes imaginarios, los novelescos y los ausentes», 41: 195-197, m. 1916; «Traducciones de versos», 76: 48-50, abr. 1919; «Algunos aspectos del feminismo», 79: 26-38, jul. 1919; «Ensayo sobre el origen y evolución de la escritura», 85-86: 18-31, en.febr. 1920; «Enrique Ochoa», 89: 219-225, m. 1920; «María Luisa Pérez Herrero», 93: 394-397, sept. 1920. 
II. Matilde Ras ha dejado documentada su relación con escritores catalanes, por ejemplo, Narcís Oller. Por su parte, la correspondencia entre Caterina Albert i Paradís, Víctor Català, y Matilde Ras, entre 1904 y 1964, permite el conocimiento de opiniones y pareceres más personales de nuestra autora sobre temas que giran en torno a la vida cultural, a la actualidad política, y a otros asuntos, como el estado de las relaciones castellano-catalanas o la atenta lectura de la obra de su interlocutora. El fondo documental conservado en la Casa Museu Víctor Català de l'Escala (Girona) cuenta con una extensa serie de cartas de Ras. Forman dichas cartas una secuencia epistolar sólida, una de las muestras más exhaustivas del respeto y devoción que la modernista catalana suscitó entre los escritores en lengua castellana, en particular durante el primer tercio del novecientos. De ese material extraemos la siguiente información para perfilar la presencia de la autora, más allá de los textos publicados y antes atendidos.

Matilde Ras se expresa en sus cartas como conocedora pasiva de la lengua catalana, dispuesta a leer en catalán a Víctor Català si acaso ella prefiriese cartearse en su idioma. Esta posibilidad queda probada mediante algún fragmento que la receptora, Ras, transcribe en su respuesta comentada. Por su parte, ella no renuncia a escribir en catalán alguna expresión o anécdota, excusando siempre su ortografía. Esgrime así un componente de su herencia cultural que se prueba también por la confesada lectura de clásicos modernos catalanes. Pero, al mismo tiempo, Ras no deja de notificar el creciente alejamiento o enemistad recíproca entre catalanes y castellanos. Como respuesta a ese debate - desde su propia modernidad, por ella misma cuestionada, o desde un liberalismo más asumidoprevé una solución buscada entre autonomismo o, en caso extremo, separatismo por parte de Cataluña, o llegando a contemplar una república federal, de acuerdo con una carta de 1918, como marco donde resolver el problema histórico de España. Ahora bien, a pesar de que su discurso pueda progresar en esa dirección, Ras verdaderamente responde a una cierta tradición del liberalismo español de expresión castellana. Dicho posicionamiento, que dice entender el caso catalán, a su vez, no deja de solicitar a sus autores que escriban también en castellano. En el caso que nos ocupa, Ras justifica su deseo de que Català produzca en esta lengua por la certeza en su competencia lingüística.

En el campo más personal, nuestra escritora siempre mostró su esperanza en la profundidad y duración de su relación con Víctor Català. La percibía como la perfecta interlocutora, sólo en alguna ocasión cuestionada por su comedimiento epistolar. Además, como grafóloga, Ras deduce perfiles psicológicos de la autora, como por ejemplo su misantropía, ligada al empeño de mantener su pseudónimo, así como sus etapas de mayor o menor energía creativa. Ciertamente, también y, por otro lado, la equipara literariamente a sus figuras artísticas más respetadas. A un mismo tiempo, pone en sus manos los escritos propios, a la espera de unos comentarios, venidos de la maestra, que sabe benévolos pero a la vez sinceros, y que la animan a seguir escribiendo. Ambas dialogan epistolarmente también sobre los condicionamientos sufridos por la mujer escritora. Pero, no obstante, notifican la moda de los nombres femeninos incorporados a la vida literaria desde inicios de siglo. Esa realidad la revisan con acidez al considerarla un reclamo del 'chou' literario de la época. Ras informa también de sus dificultades en el afianzamiento de la carrera literaria, una vez que da el paso de 
Barcelona a Madrid. Aprovecha entonces la ocasión para perfilar algún ángulo diferenciador de cada uno de esos espacios culturales. A título de información biográfica, las cartas documentan el peregrinaje peninsular de Ras, seguramente buscando su estabilidad económica. Llevado a cabo en compañía de su madre, su enfermedad y muerte se convierten en motivo de aproximación a Víctor Català, ligada también por la estrecha relación materno-filial. Gradualmente, no obstante, se van introduciendo en los textos referencias a la creciente crisis socio-política española, a la predicción de un conflicto bélico inevitable y a la guerra vivida de manera traumática.

Una de las pocas disensiones que documenta el epistolario entre maestra y admiradora es la lectura por parte de Ras del discurso de Víctor Català en los Jocs Florals de 1917, De civisme i civilitat. En particular al atender a la segunda parte, sobre «... lo moviment femení (...) i no feminista...» en el lar hispano. Ras contradice el criterio difícilmente conciliador de Català entre modernidad y tradición. Descalifica su retrato del varón meridional. A su vez enjuicia críticamente los niveles de conciencia de género por parte de la mayoría de la población femenina hispana. En ese sentido, según Ras, se considera arriesgada la concesión del sufragio a las españolas al prever la tutela de su confesor sobre cada mujer. O sobre buena parte de ellas, al menos. La carta en la que Ras plantea esta disensión no está datada. Cabe pensar que no sea necesariamente de 1917 sino, tal vez, posterior, en fechas aún más propicias para la revisión llevada a cabo sobre dicho discurso. Esto, desde una situación, posiblemente ya en la década de los veinte, que se presentaba como un escenario mudado respecto del tradicional espectro hispano en cuanto al protagonismo público y doméstico de mujeres y hombres. Matilde Ras parece pensar que tal cambio sólo era epidérmico.

Quizás en la atrasada recepción del discurso de Víctor Català opere el hipotético envío por parte de Matilde Ras de un artículo sobre la cuestión femenina. En 1919 y en Estvdio, Ras publica «Algunos aspectos del feminismo» (v. n. 4), texto que nos asegura en la diferencia de criterios conocidos por la carta mencionada. Con su artículo, Ras se adscribe al feminismo conservador, proyectado a partir de la doctrina social de la Iglesia, vertiente que en las letras catalanas documenta Dolors Monserdà con volúmenes de principio de siglo y aún más cercanos a la afirmación de nuestra autora como es el caso de Tasques socials (1916). La adscripción a esa vertiente feminista Ras no la certifica únicamente mediante la llamada final de su texto a indicios católicos. Rememora aquí la colaboración de mujeres y pueblo llano con Cristo cuando un mensaje nuevo venía a derrocar un sistema caduco, momento y vicisitudes equiparables a la coetánea crisis del «edificio de la civilización»; y estipula una fórmula de «nueva familia», surgida de un equitativo pacto de respeto entre hombre y mujer, favorable a una nueva época o «Germinal», umbral de un aspirado «ideal de justicia». El tradicionalismo de Ras alcanza a su enaltecimiento mediante su papel maternal y doméstico, al que no cabe renunciar. Desde éste, así mismo, es posible su mejora, aunque también es cierto que no se niega el reconocimiento de participación social, ni funcional ni excluyente de la profesionalización femenina fuera de la familia. En ese encuadre, y no obstante, Ras marca cuotas de avance. Por ejemplo, tratando el feminismo y la «instrucción» femenina como cuestión de 
«derecho» $\mathrm{y}$ «solidaridad» útiles para mujeres y varones; también al desenmascarar el poder en la sombra en el que las formas consensuadas y tachadas de burguesas recluyen a la mujer. Así, Ras desenmascara la figura del hombre como falso «protector», cuestiona una «moral» que reprime la «libertad de perfeccionarse» por parte de la mujer pero que a la vez es condescendiente con su servil explotación laboral. En este nivel del discurso, Matilde Ras entra en conflicto con el pactismo de Víctor Català; aún más puntualmente cuando remite a niveles de equiparación sexual y mejora social, atendiendo a los resultados diferentes alcanzados entre los sistemas septentrional y meridional. En este punto Ras enlaza con lo expresado en la citada carta, documento en el que, pensemos, su interrogante sobre la presión eclesiástica en la libre actuación femenina también la posiciona por encima del pensamiento cristiano-católico más ortodoxo.

De las cartas de Matilde Ras a Víctor Català cabe destacar las páginas que, devota lectora de la escritora, la primera dedicó a cada uno de los títulos que iba recibiendo. Hay en ese nivel epistolar lúcidos juicios y aclaraciones críticas sobre las obras de Català. Nombraremos las cuartillas dedicadas a Quatre monòlegs con interesantes apreciaciones sobre el género, y a Solitud con consideraciones ajustadas de orden estructural, al tiempo que se pregunta sobre los pasos de Mila tras su catártico descenso; también las dirigidas a su producción lírica, siendo Matilde Ras junto con Blanca de los Ríos dos de las firmas de expresión castellana que más acertaron en el desentrañamiento de la poesía de Víctor Català. Su obra lírica, ciertamente no mereció la divulgación que hasta la inmediata guerra sí logró su narrativa. Recuérdese respecto de lo segundo que Ras eligió la poesía a la hora de traducir a Català. También, respecto de lo primero, que si no reseñó ninguna traducción, sí tuvo a bien expresarse negativamente en sus cartas sobre los volúmenes de relatos trasladados por Rafael Marquina (Dramas rurales. Novelas breves y La Madre Ballena, ambos de 1921) en carta de 1931; y que sí, sin embargo, reseñó en castellano un original de la autora (La Mare-Balena, 1920 ), en uno y otro caso con equivalente clarividencia a la mostrada en las acertadas líneas epistolares sobre el resto de sus lecturas. Sólo añadiremos que entre la correspondencia intercambiada entre ambas firmas se conservan fragmentos de originales literarios de Matilde Ras, resto de aquéllos que, según notifican las cartas, ella puso en manos de su interlocutora y guía, a la espera de consejos o para que lograse su publicación (para epistolario M.R.-C.A.P., v. Ribera Llopis 2007, consultar entradas sobre Ras en Índex onomàstic, p. 337).

III. Matilde Ras, presencia que recorre con holgura la vida cultural hispana durante medio siglo, coprotagoniza, entre graduales logros y persistentes limitaciones, el primer tercio del siglo veinte. Su trayectoria confirma trabas y puertas entreabiertas para la mujer en aquel medio poblado por tantos personajes secundarios como ella misma, figuras no obstante de gran ayuda a la hora de atender a su reconstrucción histórica. El perfil de que hace gala nuestra autora responde, además, a un liberalismo intelectual practicable desde el conservadurismo o la derecha política, que alcanzó entre los años veinte y treinta del siglo pasado tanto carta de naturaleza como de viabilidad histórica. Unas cuotas positivas, culturalmente hablando, que se vieron truncadas por la exacerbación del propio discurso en torno a la guerra civil, entre su crítico preámbulo y su dicta- 
torial derivación. Así lo pueden testimoniar las cartas de Ras a Català desde 1939 y encabezadas por el significativo «Año de la Victoria». Firma crecida con el umbral del novecientos, la autora cumplió en la cronología de la II República con el mayor acercamiento a sus expectativas literarias. Escritora que no cabe entender explícitamente como republicana por su ideología, pero sí por su contexto y temporalidad, se trata de una autora que llega a ser de los tiempos de la Dictadura y de la República, aunque cabría puntualizar que con un arranque intelectual postmodernista. Los márgenes no superados de su inestable profesionalización literaria la llevarían seguramente a tomar una decisión en los primeros años de postguerra, cuando se debía haber acentuado su precariedad laboral. Hipotética huida hacia delante, y acerca de la cual tanto vale expresar el viejo sueño de visitar el país como la imposibilidad de transmitir urgencias marcadas por los sentimientos (Ras 1946: 9, 85), la estancia en Portugal entre junio de 1941 y septiembre en 1943 se recogerá en su Diario, editado en 1946 en castellano por Coimbra Editora, volumen que contará con una segunda edición madrileña en 1949.

Documento del presente de Matilde Ras - informando como de pasada haber viajado a Portugal como «cronista de guerra» (Ras 1946: 187) pero desde donde cubre para sobrevivir variados ejercicios de escritura, responder a las consultas grafológicas recibidas desde España (Ras 1946: 78, 100) o componer crónicas con los más variados contenidos-, el Diario certifica el peso del tiempo de formación y de consolidación de su autora. Una de las crónicas para Barcelona teatral, cuya génesis y contenido se relata en aquellas páginas, versa sobre una profesora de gimnasia rítmica que fue condiscípula de Nijinsky, circunstancia que suscita la rememoración de aquel otro tiempo (Ras 1946: 171172, 178-179, 183-184). Es en ese sentido en el que, de entre sus diversos planos compositivos, rescatamos el Diario como epílogo lusitano de un ciclo biográfico. Entre emotivamente añorante y dramáticamente marcado por el bélico final de aquella cronología, el Diario es fuente del paisaje dejado atrás por su autora, de las lecturas que siguen acompañándola, de las ironías con alguna excesiva sacralización de su época, así como de alguna asignatura pendiente, y también de algún momento de su poca documentada biografía. Se trata de un texto a cuyo fondo cabe acoger el alcance de una novela suya posterior, Heroísmos oscuros (1968), narración que se mueve entre los extremos del melodrama y de la alternativa al consenso social, situada así mismo entre las vivencias, que vienen de las décadas de un principio de siglo europeo abocado al ciclo bélico, y las expectativas de un ciclo en paz.

Escrito desde la cosmopolita línea de flotación que va desde Lisboa a Estoril, con un modus vivendi asegurado merced a la neutralidad portuguesa durante la segunda guerra mundial, en las páginas del Diario Matilde Ras rememora Madrid y, por extensión, España como un espacio vacío, sólo ocupado por recuerdos y tumbas, ausencias a las que únicamente cabe añadir la noticia de alguna nueva desaparición (Ras 1946: 10-11, 60-61, 273-276). Reciente pasado bélico que, como drama humano, ve perpetuado en el coetáneo conflicto mundial, Ras medita sobre la guerra en clave de amenaza contra la solidaridad humana, de distanciamiento de los seres queridos, de sentimiento de pánico que nos deja atávicamente marcados, de sensación de abandono divino debida a la iniquidad hu- 
mana, de interrogante sobre «... esta caída vertical de la civilización» (Ras 1946: 40-41, 62, 77, 96, 109, 131-132, 341-344). En ese discurso, las llamadas más específicas a la guerra española redundan en la sensación de desmemoria tal vez como patología para ahuyentar el terror acumulado, en la hospitalidad desinteresada de quienes acogieron a los que habían perdido su hogar, en el extravío de contactos personales que alimentaron nuestras vidas, en la renuncia a los objetos cotidianos que configuran nuestro imaginario (Ras 1946: 103-104, 109, 167-178, 170-171, 207, 311). Entre esa red de tristes sugestiones, emerge la recuperación de un Madrid en paz y del añorado orden doméstico como signo de otro tiempo previo a la gran debacle (Ras 1946: 78-79, 164-165, 202-203). Llevados ya por el impulso de la memoria a aquel rico preámbulo, no faltarán llamadas a la Tarragona de origen, «el mejor balcón del Mediterráneo», a los flashes de una vida que, desde la infancia, se perfiló como itinerante y fue pasando por diversas sedes y atesorando las más variadas sensaciones - la iniciación plástica en Zaragoza y la rememoración de los sabores y olores de un pasado huerto aragonés, el contraste de sensibilidades a la luz de diversas procesiones contempladas en Barcelona, Sevilla o Sigüenza, la recuperación de la estancia apacible en un «mas» catalán (Ras 1946: 116-117, 154, 242, 244, 302, 304-305, 306) - . Por su parte, los años vividos en París se recuerdan mencionando actividades culturales -idas al teatro o participación en sesiones informativas sobre la escritura de guiones cinematográficos-, ocupaciones domésticas o encuentros personales que la guerra posterior anuló (Ras 1946: 35-36, 67-68, 150$151,168-169,207)$. A propósito de su formación, actividad y obra grafológica, estrechamente relacionada con la permanencia parisina, cabe recordar con la autora que «Se conocía, cuando yo empecé, muy poco la grafología en España» y cómo, a su favor, ella atendió a las enseñanzas de las primeras firmas en la materia pasando por la mencionada Societé de Graphologie de París (Ras 1946: 211-213).

Fue, en suma, todo un tiempo marcado por unos iconos culturales que lleva Matilde Ras en su viaje geográfico y biográfico. Constan las relecturas nunca abandonadas de Homero, Cervantes, Shakespeare, Goethe o de los abanderados de la novelística decimonónica. A todos ellos los acompañan referencias continuadas a maestros de la pintura y de la música, a la relevancia íntima de cuyos nombres Ras nos acostumbrará desde las líneas de su epistolario con Víctor Català. La autora, no obstante, nunca ajena al presente inmediato literario, va y vuelve insistentemente sobre firmas y títulos vigentes desde su tiempo de formación y de crecimiento intelectual. Huxley, Cocteau, Fayard, Zilahy, Proust, Pessoa, Morand, Zweig, Maurois, Kipling, Amiel, Loti, Azorín, Michaëlis de Vasconcelos, Unamuno, Lagerlof, Valéry, Ortega, Erckmann-Chatrian..., bajo el amparo lírico aún de los románticos Wilde, Byron, Heine, Poe, Baudelaire, Verlaine, Rimbaud, Florbela Espanca, Bécquer o Antero de Quental (Ras 1946: 18, 23, 25, $38,43,44,50,51,52,53-54,56,72,89,91,92,94,98-99,117,118,123-124$, $130,160-161,166,187,198,200,221,249,258,296,303,322)$. En aquel medio intelectual reconoce alguna carencia personal como la lectura pendiente de Joyce (Ras 1946: 200-201). También es cierto, guarda de aquel primer tercio de siglo conciencia sobre alguna que otra excesiva reverencia, ya fuera el culto a Freud o la fascinación ante las naturales limitaciones del incipiente cinematógrafo (Ras 
1946: 34-36, 257-258, 329), frente al teatro (Ras 1946: 34, 68). Lo primero con cordial ironía sobre el afán freudiano de interpretar signos, quizás más sobre la derivación freudiana que sobre la obra del maestro vienés (Ras 1946: 70-71); lo otro prestando atención a cómo la novedad de la imagen en movimiento hace olvidar lo endeble del argumento de los primeros filmes. Junto con esta apreciación negativa hay otras que muestran el interés por el nuevo arte (Ras 1946: 34-36, 64). No obstante y respecto al cinematógrafo, sabremos merced al Diario que el mencionado aprendizaje parisino llevó a Matilde Ras a escribir guiones en colaboración con Cecilio de Valcárcel, con unos resultados que, como otros tantos textos suyos, pasaron de inéditos a extraviados (Ras 1946: 307-308). Conoceremos así mismo la noticia recibida en Portugal de que su teatro publicado en 1934 había sido representado en Valencia. Aprovecha esta información para rememorar que otra obra suya, La hermosa hilandera y los siete pretendientes, había subido a las tablas en Panamá de acuerdo con la carta del grupo de teatro estudiantil que llevó a cabo la representación. Lo uno y lo otro lo expresa transmitiendo la extraña sensación de no haber llegado a ver con vida dramática a sus criaturas escénicas (Ras 1946: 306-307). Y también, a través de sus páginas, quedará probada la estrecha relación con Elena Fortún -también escritora con pseudónimo, Encarnación Aragoneses Urquijo, y feminista irredenta—, desde su exilio en Argentina, amistad constantemente expresada a lo largo del libro junto con trascripción de cartas recibidas, nombre al cual, además, se dedica el Diario (Ras 1946: 54, 83, 96, 123). Respecto a esta última cuestión de las amistades literarias, dicho libro notifica la recuperación del intercambio epistolar tras la contienda por parte de Víctor Català (Ras 1946: 185-187).

El volumen lusitano de Matilde Ras revisado con la intención señalada de mirar hacia la época anterior a la guerra, habla además sobre otras cuestiones. Unas íntimas, como la consecución de la felicidad y la constancia necesaria de la voluntad (Ras 1946: 229, 334). Son estos valores que recorren todo el peregrinaje biográfico de la autora y que debieron serle de intangible valor, como la ilusión y el esfuerzo de aquellos años pasados que, iniciada la década de los cuarenta, dejaba atrás. Otras cuestiones sociales, como la percepción de la diversidad entre Portugal y España y entre los hábitos de sus nativos (Ras 1946: $10,11,14,106,115,121)$ y sus relaciones literarias portuguesas. Matilde Ras contactó en Portugal con escritoras de primera fila y de discurso feminista como Virgínia Victorino y Virgínia de Castro, o con otros creadores como Ricardo Serra o Eugenio de Andrade (Ras 1946: 101, 103, 106-107, 111-112, 119-122, 194-195, 223-224, 241, 296). Sobre las dos escritoras mencionadas cabe destacar, además, que reflejan el espíritu que Matilde Ras admiraba en las mujeres: personalidades fuertes, revolucionarias y de perfil excéntrico para la época. Pero estos asuntos que ciertamente se imbrican en los resumidos, han de reservarse para una ocasión futura.

\section{ROSA M. ARQUIMBAU (1910-1992).}

I. La historiografia literaria ha sido revisada como disciplina filológica con tendencia a la convención repetitiva, a la mímesis inalterable, incluso, al plagio 
consensuado (Guillén 1985: 363). Esta factible perpetuación diacrónica, con nómina de firmas y documentos que prueban la duradora panorámica un día establecida, desestima datos no fijados en aquel momento, omite nombres no contemplados de acuerdo con un criterio ya remoto o no incorporados por falta de una cierta recuperación de fuentes, al mismo tiempo que excluye títulos cuya presencia, bastante condicionada por la propia época, permanece a la espera de un decidido paso hacia la arqueología literaria. Si se actúa en contra de aquella perspectiva repetitivamente complaciente, hasta nos podemos encontrar con el redescubrimiento de una documentación digna desde un punto de vista estético e incorporable al canon fijado de una determinada etapa literaria; al menos, podremos restaurar unos documentos que den soporte espectral a hechos, títulos y patronímicos consagrados y haremos volver a los individuos culturalmente activos que, con aciertos, limitaciones y determinadas cuotas de validez artística, configuraron el entramado de una vida literaria que, de otro modo, permanecería falta de aliento, allí donde los clásicos consensuados respirarán como criaturas huérfanas. Quede claro, de entrada, que esta última consideración está hecha sin el apriori de querer diseñar alguna presencia hasta ahora intencionalmente omitida con el objetivo de cuestionar el material historiográfico existente. No hay que exagerar el victimismo y focalizar en exceso ninguna figura silenciada a propósito como artista maudit; por el contrario, nos hemos de acercar para poner de manifiesto su valor específico y su protagonismo cultural. La labor recuperadora de material desconocido o que no había visto la luz responde también al deseo de nutrir objetivamente el entramado literario. Siguiendo estos criterios contribuimos a resituar la figura de Carles Sindreu (Madrenas, Ribera 2001); con idéntico rigor queremos acercarnos ahora a Rosa M. Arquimbau. Desde una primera y parcial recuperación de su obra de preguerra, asumimos contar con el conocimiento de una firma que nos explicaba, al lado de las otras escritoras coetáneas, el establecimiento de una enciclopedia temática y de un lenguaje narrativo que no resultarían indiferentes a narradores de la siguiente promoción (Madrenas, Ribera 2002-a); y, además, la consolidación durante la posguerra de una densa narrativa en tan solo dos volúmenes —La pau és un interval (1970), Quaranta anys perduts (1971)—, su consistencia discursiva, así como su desencantado cierre, arraigan en las expectativas históricas documentadas en la producción periodística previa y en la desperdiciada conclusión del siglo (Madrenas, Ribera 2002-b).

$\mathrm{Si}$, para nosotros, aquel vaivén entre, por una parte, una narradora primeriza de evidentes limitaciones, que era al mismo tiempo una columnista de punzante actualidad y claridad discursiva y, por otra, una novelista al fin sólida, en buena medida por los orígenes y por la praxis ideológica, a pesar de estar editorialmente desaprovechada, si eso, insistimos, nos aproximaba, nada más pasar el umbral del nuevo milenio, a una presencia historiográficamente minorizada a la vez que culturalmente y creativamente atractiva, es evidente que el horizonte de Rosa M. Arquimbau en el panorama de la historia de las letras catalanas ha variado de manera notoria. Como caso ejemplar de restauración, hemos de empezar por decir que la autora no aparecía en el compendio de literatura contemporánea de J. Fuster (1978) donde se ordenan, además de primeras firmas, otras representativas de figuras que, en determinados momentos, destacaron más 
como activistas culturales que como sólidos creadores; ni tampoco en los volúmenes de la HLC (Molas 1988), que contienen una documentación ciertamente plural, aunque sí constaba ya en el diccionario dirigido por J. Molas y J. Massot i Muntaner (1979: 56). Desde aquí, no obstante y haciendo un salto cualitativo, Rosa M. Arquimbau ha pasado a incorporarse en las nóminas representativas de la literatura catalana que, con un planteamiento global, ofrece el nuevo diccionario dirigido por E. Bou (2000: 50); con anterioridad y bajo unas premisas ginocríticas, la ordenación de K. Macnerney y C. Enríquez de Salamanca (1994: 59-60) - tal vez origen de la ampliación de datos del último diccionario mencionado-, así como el título hoy en día revisable de A. Charlon (1990) pueden estar en el principio del interés lector por nuestra autora y por alguna otra compañera generacional, a propósito de las cuales se podría tomar en consideración el recordatorio histórico de A. Murià (1988: 51) que dejaba constancia de cómo, progresivamente, la obra de Rosa M. Arquimbau acabó por pasar desapercibida. Queda por añadir, para completar este sucinto abanico de referencias, la breve pincelada que mereció el teatro de la autora por parte de L. Hernández (1994)

Sobre la bibliografía que alcanza la línea cronológica del dos mil —más allá de nuestros particulares hallazgos y llamadas de atención- o de aquella aportación que ya sitúa a la escritora en el concierto de autores de preguerra en Cataluña, centrándose en escritos sobre cultura física (Johnson 2004), las monografías de N. Real (2006-a, 2006-b) han fundamentado el protagonismo y la lectura crítica de Rosa M. Arquimbau en el marco historiográficamente revisable de la República y la preguerra. Con treinta y una y treinta y ocho entradas, respectivamente - que no han tenido en cuenta alguna aportación previa, dicho sea de paso, suponemos que por aquello del destino desaprovechado de los volúmenes de actas-, Rosa M. Arquimbau queda incorporada al corpus estable de escritoras del periodo mencionado y nos consta como una voz directamente implicada en las tensiones coetáneas, sobre todo, desde sus páginas periodísticas. En estos dos estudios, además, queda trazada la trayectoria literaria de la autora, desde las razones de su inicio hasta su evolución, y también por medio de su producción narrativa pasando por el inexcusable contraste con sus artículos; queda establecida, asimismo, la red de vínculos, modelos y conceptos operativos en su producción, y es recuperada la crítica coetánea merecida, al mismo tiempo que se constata la relevancia de Rosa M. Arquimbau y de Anna Murià, Aurora Bertrana y M. Teresa Vernet, juntamente con la primera Mercè Rodoreda, en el reconocimiento que empezó a tener la novelística femenina.

II. Podemos, por tanto y todavía, hablar de la presencia y de los papeles pendientes de Rosa M. Arquimbau. De acuerdo con la restauración historiográfica y, al fin, crítica que hemos revisado, la contundencia de esa aseveración pudiera ser gratuita o, cuanto menos, osada. A pesar de ello, quizá podríamos aprovecharla y resultaría sugeridora si nos permite prever, primero, que desde las aportaciones mencionadas la autora pase definitivamente a los compendios literarios que en este inicio de siglo puedan llevarse a cabo; segundo, que su material periodístico recuperado en los anteriores trabajos, más que digno histórico-culturalmente hablando y en la línea de los columnistas más reconocidos de la época, sea vehiculado por editoriales con previsible repercusión, tal y como en su tiempo y 
recientemente ha sucedido con Josep M. de Sagarra y Carles Soldevila, objetos de coincidentes reediciones en el año 2004, y con Aurora Bertrana en 2007; tercero, que su novelística de posguerra - superadora de la narrativa primera que, no obstante, habría sido taller de los aciertos posteriores - vuelva a los catálogos editoriales donde, tal vez, correría una sorprendente carrera o, al menos, cubriría algún vacío en la evolución de la novela catalana del novecientos. Y, aún, por lo que respecta a la obra literaria inicial, cabría preguntarse por posibles inéditos, al tiempo que seguir con su búsqueda; escritos sin los cuales cuesta entender su salto cualitativo entre prolegómenos y títulos de madurez; también nos deberíamos interesar por hipotéticos papeles memoriales o sencillas anotaciones autobiográficas que consideramos anteriores a determinados episodios de las dos últimas novelas (Madrenas, Ribera 2002-b: 131); porque habría que saber, en cualquier caso, si, aparte de los títulos de teatro que se estrenaban con éxito o «el recull de contes que té inèdits» llegó a existir o eran alusiones con las cuales se redondea un perfil literario cuando se presenta otra obra, dando por existente aquello que no pasa de proyecto. Ambas menciones sobre el teatro y la narrativa breve de la autora se incluyen en la página de presentación, firmada por A. Bernal, de L'inconvenient de dir-se Martines, obra con la que volvió a la escena de posguerra (Arquimbau 1958: 87). Otros papeles pendientes de los cuales cabría averiguar, de confirmarse el hallazgo, si eran anteriores a 1939 y habrían sido recuperados para relanzar la propia y nueva presencia $\mathrm{o}$, tal vez, serían producto de nueva creación, tocada por el desencanto histórico que culminan las dos novelas finales y desde las cuales se observa el período de formación como una cepa yerma. Pensamos que, por parte de Rosa M. Arquimbau, existe referencia a títulos propios no comprobados bibliográficamente, como por ejemplo la novela «enllestida» Adéu si te'n vas... que había de aparecer en la «Biblioteca A Tot Vent», según el anuncio incluido en la presentación de Home i dona (1936), texto a propósito del cual N. Real (2006-b: 169, n. 169) ha formulado hipótesis sobre su existencia y reconversión textual; a estas conjeturas vendría a sumarse el peso que tuvo la fecha del inicio bélico en la interrupción de proyectos editoriales.

III. Lo que sí queda pendiente de realización en la esbozada red de aportaciones sobre la presencia de Rosa M. Arquimbau, hoy por hoy, es llevar a cabo la búsqueda de unos hipotéticos papeles inéditos. Si es posible la recuperación de algún relato y, en particular, de las mencionadas notas autobiográficas que habrían de recorrer subterráneamente momentos de las dos novelas de posguerra, hemos de reconocer que las pesquisas realizadas por nuestra parte hasta el momento no han llegado a buen puerto. Con el ánimo de intentar compensar este contratiempo, nos queda el recurso de ensayar posibilidades lectoras de la obra primeriza de la autora que propicien su restauración crítica. Ya N. Real ha desarrollado a fondo y con solvencia la correlación entre discurso narrativo y teórico, sobre el «... paral-lel novel-lístic dels articles de l'escriptora» (Real 2006-b: 184) y viceversa, lo cual contribuye al esclarecimiento de los márgenes de su modernidad; una labor que ha efectuado mediante un estudio contrastivo entre textos que, en nuestro previo estudio, anteriormente citado, ya nos permitió percatarnos de la perspectiva desde la cual se rememoraba el pasado en las dos últimas novelas y, difícilmente, se vislumbraba un futuro coherente, valiéndonos 
de documentos periodísticos y narrativos de preguerra y con la finalidad de reconocer fondo y fuentes a la hora de armar la propia memoria novelada (Madrenas, Ribera 2002-b: 127-132).

Con estos márgenes preestablecidos de actuación, emprendemos la senda alternativa de sugerir tácticas de lectura de la obra de Rosa M. Arquimbau, por la que nos hemos decidido, acogiéndonos a una posibilidad que ya no nos habla de interacción textual, sino de intersección genealógica. Lo que ciertamente se podría intentar probar desde los artículos firmados por quien suele mencionarse como referente de las columnas de Arquimbau, Josep M. de Sagarra con sus aperitius, lo hemos trabajado con anterioridad desde otro modelo coetáneo, Carles Soldevila y sus fulls dietarístics. Nos referimos a la proyección hacia el artículo de retórica, estructura y recursos narratológicos, paralelamente a cómo ciertos relatos pueden convertirse en espejo funcional de la exposición periodística. Esta convergencia en doble dirección de espacio de opinión y estadio de creación - a la cual tampoco son ajenas las bonhomies carnerianas a pesar de que se destacan más a menudo sus parámetros líricos- nos llevó a reconocer, en el caso de Soldevila, tanto la existencia de cuentos-artículo como que la gradual reducción de la escritura de relatos por parte del autor —en función de la creciente tarea novelística desde un determinado momento de su trayectoria literaria-, lo haría recluirse, como cuentista, en el cultivo del columnismo como reducto donde practicar las artes conseguidas a favor de la narrativa breve (Ribera 2002: XI). Si por lo que respecta a la primera Arquimbau se puede coincidir en que, según Cèsar A. Jordana el año 1934, su «... vàlua [...] és més social que literària» (Real 2006-b: 370) y la misma autora se había manifestado desde $L a$ Rambla (2-III-1931, n. 49, p. 7) (Real 2006-b: 91-92) e insistía desde las páginas de L'Opinió (17-VII-1932, n. 350, p. 5), a propósito de la mujer, la literatura, la lectura y el mercado de la novela, sobre la urgencia de proyectar por encima de los libros manipulados por muchas jóvenes unos mínimos de calidad correctores de la condición femenina - a partir de los clásicos contemporáneos como modelos sustitutorios de los maltrechos patrones traducidos que llegan a aquellas manos-, podemos concluir que la concepción literaria de la autora era bastante socioeducativa. Si Arquimbau entendía que, a favor de la novela y de su función educadora, era necesaria la exigencia argumental, es decir de contenidos coincidentes con los que ella y otras activistas trataban directamente desde los periódicos (así en 1934, en Clarisme, v. Real 2006-b, 94), seguro que habría de calcular que ciertas maneras narrativas facilitarían el acceso a estos otros papeles, y lo puso en práctica. En torno a esta hipótesis sería conveniente revisar una serie de artículos de la autora y tener en cuenta, al mismo tiempo, con el criterio aclarado desde la perspectiva apuntada, una colección de relatos. A tal fin, hemos escogido los publicados en Imatges (1930) y en L'Opinió (1932-1934) y la recopilación La dona dels ulls que parlaven i altres contes (1930), respectivamente.

Empezando por la segunda fuente mencionada, juega en contra de nuestro interés la factura mayoritaria de sus artículos. Tratan temas candentes con voluntad de crear opinión y optan por una retórica que encaja con la palabra «crònica» que tantas veces encontramos en el mismo texto, crónica como relación de un hecho o de una situación, sin obviar, no obstante, la sentencia o la propuesta 
por parte de la autora. Para detectar en este material recursos procedentes de los géneros más creativos, no podemos tener en demasiada consideración, no obstante, ciertos usos como por ejemplo el diálogo en «Reportatge imaginari» (1-V1932 , n.290, p.1), tratándose como se trata de un interwiew pese a ser ficticio. El uso es literariamente más explícito cuando hay que pasar por un fragmento descriptivo, que contextualiza un espacio donde algunos sujetos evidenciarán una presencia y emitirán unos juicios o, en todo caso, actuarán de una determinada manera, justificando la conclusión de la autora como en «Hem estat a Vilamar» (31-VII-1932, n. 362, p. 5), en «Temes d'estiu» (21-IX-1932, n. 38, p. 5) o en el bloque de artículos dedicados a visitas y consideraciones sociales sobre determinados asilos (30-IV-1933, n. 595, p. 13; 6-V-1933, n. 599, pp. 1 y 12; 15VI-1933, n. 634, p. 7; 10-VIII-1933, n. 681, p. 9). En ocasiones, es el anecdotario interno del artículo, que ejemplifica su tesis, el que permite una abreviada relación, así en «Espionatge» (25-IX-1932, n. 410, p. 7), donde se recupera el retrato de Mata-Hari y se recorren los pasos menos conocidos de Anna Maria Lesses. De los retratos se puede pasar, a veces, a la relación de arquetipos sociales - así con algunos prototipos femeninos de factura americana en «Standard» (2-XI-1932, n. 416, p. 7) —, o bien insistiendo en el de la vampiressa y deteniéndose descriptivamente en la composición de su toilette, como en el caso de «L'uniforme de les vampiresses» (5-XII-1932, n. 445, p. 4). Por esta vía llegaríamos a darnos cuenta de que, en dirección contraria, las consideraciones hechas a propósito de «Marit i Muller» y «Homes i Dones» (21-I-1933, n. 510, p. 6,28-II-1933, n. 516, p. 8) podrían pasar a los momentos más teorizantes de las nouvelles de la autora.

Este hilo conductor que hay que reconocer muy delgado - espacializaciones bien concretas, anécdotas que no van más allá de ser parte de un episodio de un hipotético argumento, retratos externos o éticos, voces bastante condicionadas- amplia su grueso si cambiamos de páginas. Concretamente, en las colaboraciones de Imatges, el soporte fotográfico es bien aprovechado por Arquimbau. Después de las pinceladas justas de entrada, la autora concede voz desde el texto a los protagonistas de las fotografías, como en los casos de «Els memorialistes de la Virreina» o de «Una cosa és un camàlic i una altra un mosso de corda» (16-VII-1930, n. 6; 22-X-1930, n. 20); otras veces desarrolla descripciones y consideraciones que van y vienen, con complicidad, entre línea e ilustración («Els gitanos de Barcelona», 27-VIII-1930, n. 12). Esta interacción parece acentuarse cuando el paseo fotográfico y el tema tratado discurren por ámbitos que animan la picardía, el sonido de voces o el cruce de tipos como en «Melons valencians del Prat» o en «Els Encants Nous de Barcelona» (24-IX1930, n. 16; 1-X-1930, n. 17). El texto, no obstante y prioritariamente, puede detenerse en el detalle e incluso acumularlos en correspondencia con los objetos amontonados en las fotografías, aquellos que parecen salirse de sus límites, tal y como los productos en venta en «Als encants vells» (29-X-1930, n. 21), espectáculo sobre el cual Arquimbau fluctúa irónica y, a la vez, tiernamente añorante. Es curioso comprobar cómo su prosodia cambia cuando, por ejemplo, ha de manejar imágenes y noticias que remiten a una actualidad más inmediata. En este caso, vuelve al modelo de crónica antes mencionado, aunque sólo sea para acercarse a la actualidad cinematográfica en «Buster Keaton ha fet un film par- 
lat en espanyol»o en «Lawrence Tibbet, la gran revelació del cinema sonor» (13-VIII-1930, n. 10; 20-VIII-1930, n. 11). Puede pensarse en un parámetro entre tema tratado y forma expresiva. Parece que un cierto costumbrismo temático, que no evita una composición formalmente actual, anima una escritura más literaria que no aquellos temas que se presentan como de rabiosa modernidad y sobre los cuales debía informar.

Llegados a este punto, nos queda por revisar el conjunto de relatos de Arquimbau, textos que, dicho sea de paso, no tuvimos en consideración en ninguna de nuestras dos anteriores aproximaciones a la escritora. En sus diez cuentos tienen cabida diversas aristas, incluido un inicio que parece de artículo (Arquimbau 1930: 121). Con todo, hay que reconocer que los textos se insertan de manera satisfactoria entre las constantes de la autora, en total armonía con su concepto de modernidad, mayoritariamente enfocada desde y sobre la existencia de la pareja o, si se quiere, desde la dialéctica hombre/mujer. Este tándem que suscita sus argumentaciones encaja por medio de signos externos - referencias a actores y films, automóviles, carreteras y accidentes, nuevos arquetipos de mujer, revistas femeninas y cosmética, compras y clubs sociales, taxis y chóferes con uniforme, pretensiones de refinamientos y manías de civilización o uso de extranjerismos-, articulados sobre planteamientos internos del mismo discurso - la pareja, la alternativa del amante, el opuesto amor/pasión, la constancia del placer, la iniciación erótica y el deseo, la notificación del aborto, los tópicos relativos a la dignidad masculina y el sentimentalismo femenino, la independencia económica de la mujer, el matrimonio de conveniencia, el amor libre, la transigencia entre marido y mujer como modus viven$d i$, el equilibrio amistad-amor entre hombre y mujer-. Con todo este entramado Arquimbau pergeña unos relatos que no dejan de lado tampoco el rendimiento irónico de introducirse en parcelas como el componente o el sentimiento religioso - «Teresa redempta», «La vergonya!»—o que alcanzan un grado de autonomía del argumento - «Un cas d'anèmia»—, en los límites del histrionismo, que recuerdan la representación temática de alguna de sus obras teatrales, como Es rifa un home! (1935) o L'inconvenient de dir-se Martines (1958). El resultado de todo ello son unos textos con una fluidez de formas y con una solvencia argumental más que aceptables.

Con estos dos puntos de referencia - determinados artículos y la citada colección de cuentos- se puede argüir que, sin renunciar a su credo intelectual, cuando Arquimbau opta por el componente más literario - en los artículos como medio expositivo, en los cuentos como estricta creatividad- su escritura no queda constreñida por ningún molde preconcebido. Esto que no debería ser una limitación en el caso de la crónica o artículo de tesis, quizá sí oscurece el horizonte de los restantes textos narrativos o nouvelles, como Història d'una noia $i$ vint braçalets (1934) o el ya mencionado título Home i dona. Marcadas más dogmáticamente por un mensaje — a pesar de que los iconos empleados no difieran de los que hemos enumerado a propósito de los cuentos anteriores, incluso externamente por unas formas de modernidad narrativa que en ellos emplea con más naturalidad-, dichas nouvelles se nos presentan como un callejón sin salida desde el punto de vista literario; nos parecen como una propuesta sacrificada en nombre de una transitoria concepción de la modernidad. Por su par- 
te, cuando el ejercicio de escritura —el de estos cuentos y de según qué artículos- tiene menos condicionantes en este sentido, se convierte en la prueba de una literariedad de más amplio recorrido; tal vez son el umbral de o el nexo con el que la autora conectaría años después. A la espera del hallazgo de unos $p a-$ peles pendientes de Rosa M. Arquimbau, los que a día de hoy tenemos a nuestro alcance son los documentos que dirigen hacia su consolidación narrativa, la que podría afianzar su presencia entre nosotros.

\section{REFERENCIAS BIBLIOGRÁFICAS}

\section{Ediciones consultadas}

ARQUIMBAU*, Rosa M. La dona dels ulls que parlaven i altres contes. Barcelona: Editorial Lux, 1930, Col. Balagué, Sèrie Fèmina, vol. I.

Es rifa un home!. Barcelona: Llibreria Bonavia, 1935, La Escena Catalana, n. 414.

Home i dona. Barcelona: Quaderns Literaris, 1936.

L'nconvenient de dir-se Martines. Barcelona: Editorial Nereida, 1958, Biblioteca Gresol, vol. 29.

RAs*, Matilde. Donde se bifurca el sendero. Barcelona: La Académica - Casa Editorial Estvdio, 1913.

(y AngÉlico, Halma; ValderRAMa, Pilar de). Teatro de mujeres: tres autoras españolas. Prólogo de C. de Castro. Madrid: Aguilar, 1934.

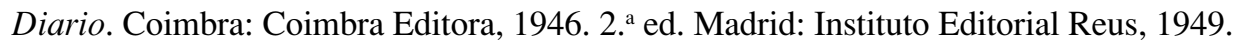

Charito y sus hermanas. Madrid: Aguilar, s. a. / 1946.

Heroísmos oscuros. Madrid: Cid, 1968.

\section{Historia y crítica literaria}

Bou, E. (dir.) (2000): Nou Diccionari de Literatura Catalana, Barcelona, Edicions 62.

Charlon, A. (1990): La condició de la dona en la narrativa femenina catalana (19001983), Barcelona, Edicions 62.

FALCón, L.; Simona, E. (1992): Mujeres escritoras. Catálogo de escritoras españolas en lengua castellana (1860-1992), Madrid, Comunidad de Madrid.

FUSTER, J. (1978): Literatura catalana contemporània, Barcelona, Curial.

HERnÁNDEZ, L. (1994): «Teatres de dones», Dona i teatre, Barcelona, Institut Català de la dona.

\footnotetext{
* No se repiten referencias de los artículos de las autoras, respectivamente, en Imatges (1930) y L'Opinió (1932-1934), y en Estvdio (1913-1920), ordenadas éstas dentro del texto y, en el segundo caso, también en las notas a pie de página.
} 
GUILLÉN, C. (1985): Entre lo uno y lo diverso. Introducción a la literatura comparada, Barcelona, Editorial Crítica.

Gullón, R. (dir.) (1993): Diccionario de Literatura Española e Hispanoamericana, Madrid, Alianza Editorial - Quinto Centenario.

Johnson, P. L. (2004): «Woman Writing on Physical Culture in Pre-Civil War Catalonia», Working Paper, University of Sheffield.

Madrenas, D.; Ribera, J. M. (2001): «Carles Sindreu, prosista», Carles Sindreu (19002000), AAVV, Barcelona, Generalitat de Catalunya - Departament de Cultura ILLC, pp. 31-40.

- (2002-a): «Anotacions a propòsit de Maria Aurèlia Capmany i la novel.lística femenina dels anys vint i trenta», Maria Aurèlia Capmany: l'afirmació en la paraula, M. Palau y R.-D. Martínez (eds.), Valls, Edicions Cossetània, pp. 169-180.

- (2002-b): «Les novel.listes dels anys 20 i 30 i la memoria novel.lada: Rosa M. Arquimbau», Memoria i literatura. La construcció del subjecte femení. Periodisme $i$ autobiografía, a cargo de J. Espinós et alii, Alacant - València, Dene editorial, pp. 125-133.

McNerney, K.; EnRíQuez de Salamanca, C. (eds.) (1994): Double Minorities of Spain. A bio-bibliographic Guide to Woman of the Catalan, Galician and Basque Countries, New York, MLAA.

MolAs, J. (dir.) (1988): Història de la Literatura Catalana, Barcelona, Ariel, vols. 10 y 11 .

Molas, J., Massot i Muntaner, J. (dirs.) (1979): Diccionari de la Literatura Catalana, Barcelona, Edicions 62.

MuRIÀ, A. (1988): «El temps i les escriptores de la II República», Literatura de dones: una visió del món, AAVV, Barcelona, laSal, Edicions de les dones, pp. 41-53.

Real Mercadal, N. (2006-a): Dona i literatura a la Catalunya de preguerra, Barcelona, PAM.

- (2006-b): Les novel.listes dels anys trenta, Barcelona, PAM.

RiberA, J. M. (2002): «Introducció», Fanny de C. Soldevila, Barcelona, Edicions 62, pp. I-LXII.

- (2007): Projecció i recepció hispanes de Caterina Albert i Paradís, Víctor Català i de la seva obra, Girona, CCG Edicions.

SAINZ De Robles, F. C. (1973): Ensayo de Diccionario de la Literatura (T. II. Escritores españoles e hispanoamericanos), Madrid, Aguilar. 